\title{
A study exploring the autism awareness of students attending the department of pre-school teacher education of a public University in Istanbul, Turkey
}

\author{
Seyhan HIDIROGLUㄹ (D), Nimet Emel LULECI ${ }^{1}$ (D), Melda KARAVUS ${ }^{1}$ (D), Seyma GORCIN KARAKETIR ${ }^{1}$ (D), Ahmet KARAVUS² \\ Department of Public Health, School of Medicine, Marmara University, Maltepe, Istanbul, Turkey. \\ 2 Otorhinolaryngology Clinic, Republic of Turkey, Ministry of Health, Istanbul Provincal Health Directorate, Fatih Sultan Mehmet Training and \\ Research Hospital, Istanbul, Turkey.
}

Corresponding Author: Seyma Gorcin KARAKETIR E-mail: gorcin_eseyma@hotmail.com

Submitted: $13.12 .2019 \quad$ Accepted: 09.03.2020

\section{ABSTRACT}

Objectives: Early detection of autism might largely depend on pre-school teachers' awareness and their prompt referral of these children to health authorities for accurate diagnosis. The purpose of our study was to assess the awareness about childhood autism among students attending the Department of Pre-school Teacher Education of a public university.

Materials and Methods: This descriptive study was carried out on 181 out of 218 students.

Results: The best known characteristic of a child having autism was "having a hard time in social relations" (90.1\%). The majority (85.6\%) of the study group believed that autism was curable and thought that a child having autism could pursue a family life in the future with his/her spouse (51.3\%). Around $60.7 \%$ of all participants were of the opinion that a child with autism cannot participate in conversations.

Conclusion: The idea of a child with autism disturbing the teaching environment (50.8\%) exists which might be a very important obstacle for his/her education; thus interfering with his/her treatment. Autism awareness of respondents could be considered to be relatively good among the senior students.

Keywords : Autism, Awareness, Pre-school Teaching, University Students

\section{INTRODUCTION}

Autism disorder was first described in 1943 by the American child psychologist, Leo Kanner [1]. Autism is considered as a neurodevelopmental condition interfering with the person's ability to communicate and relate to others [2]. Prevalence rates have been rising sharply and are estimated to be one in 50 amongst children $[3,4]$.

Many studies show that early diagnosis enables prompt initiation of appropriate therapy and early intervention aiding in their development and improving their communication and social skills [5-10]. Diagnosis at younger ages plays a crucial role in prognosis and developmental outcomes [8, 10]. Interventions may have diminished effectiveness in older children [8]. However, the length of time from a parent's first notice of symptoms to the time of diagnosis is reported to be relatively long, leading to delayed diagnosis and intervention [10]. Outside of parents and care-givers, pre-school teachers are the group most likely to spend the longest time and the closest relations with small children having autism in the early years of life $[5,8]$. Early identification might largely depend on preschool teachers' knowledge and awareness about autism and their attitudes towards interventions [5-10]. Their ability to pick out children with autism in the classroom is beneficial in the long term [5]. The Illinois Weselan University greatly emphasizes the role of teacher training in not only identification but also management of autism spectrum disorders in infancy [5]. Furthermore pre-school teachers must be able to not only identify children with developmental problems but also refer them to appropriate health authorities [7]; from thereon they can take a role in family support services [10].

To this end, the purpose of the current study was to assess the awareness of childhood autism among students attending

How to cite this article: Hidiroglu S, Luleci NE, Karavus M, Gorcin Karaketir S, Karavus A. A study exploring the autism awareness of students attending the department of pre-school teacher education of a public University in Istanbul, Turkey. Marmara Med J 2020;33(2): 90-96 doi: 10.5472/marumj.741719 
the Department of Pre-school Teacher Education of a public university in a metropolitan city, Istanbul, Turkey.

\section{MATERIALS and METHODS}

\section{Participants}

This descriptive study was conducted on students attending the Department of Pre-school Teacher Education of a public university in Istanbul, Turkey, in April 2015. A population of 192 out of 218 first grade and fourth grade students who gave informed consent to be a participant were admitted to our study.

This study was approved by Marmara University Ethics Committee. All procedures performed in this study were in accordance with the ethical standards.

\section{Instrumentation}

Data was collected using a self-administered questionnaire. Out of 192 questionnaires, 11 questionnaires were excluded due to missing answers. Finally, 181 were found adequate to be included in the current study. This study was composed of 100 students attending first grade and 81 students attending the fourth grade. Nineteen autism awareness assessment questions were present in the questionnaire being made up of true (1 point) and false/ do not know (0 points).

Questions about "autism awareness" were prepared referring to The Validity and Reliability of the Social Communication Skills Scale for Pre-school Children (Turkish version) study carried out by Öner et al. [11]; besides "Using the modified checklist for autism in toddlers in a well-child clinic in Turkey: Adapting the screening method based on culture and setting" prepared by Kara et al. [12] and also using "Knowledge About Childhood Autism among Health Workers (KCAHW)" questionnaire developed by Bakare et al. [13].

Since, we were unable to find a scale/questionnaire inquiring The Autism Awareness of Pre-school Teachers we had to prepare our own questionnaire. After deep review of the current literature, we believed that the above-mentioned three questionnaires/ scales/checklists would be the best to prepare such a questionnaire. Questions that are more decisive in recognizing autism spectrum disorder and important for pre-school teachers to know were chosen and included in the questionnaire. The questions were evaluated based on the frequency of correct answers to each question without determining the cut-off point. In other words no cut-off point was used. True answer was the correct response for each question. This might be considered as a limitation of our questionnaire.

\section{Statistical Analysis}

Descriptive analyses were presented using tables of frequencies for the ordinal variable. The Chi-square test or Fisher's exact test (when chi-square test assumptions do not hold due to low expected cell counts), where appropriate, was used to compare these proportions in different groups. A p-value of less than 0.05 was considered to show statistically significant result.

\section{RESULTS}

This descriptive study was conducted on 100 first grade and 81 fourth grade students attending the Department of Pre-school Teacher Education of a Public University in Istanbul, Turkey. Of all respondents, 156 students $(86.2 \%)$ were females and 25 students $(13.8 \%)$ were males. The mean age of the total of 181 students was $21.04 \pm 2.89(\min 19, \max 44)$.

The best-known characteristic of a child having autism was "having a hard time in social relations" with a percentage of 90.1\%; not distributed statistically significantly between the grades (Table I; $>>0.05$ ). Based on other results presented in Table I, we can observe that $158(87.3 \%)$ of the respondents were aware that a child having autism can have language delay $\left(x^{2}=2.773 ; \mathrm{p}>0.05\right)$. A total of $98(54.1 \%)$ students were aware that children having autism cannot express themselves using gestures, showing statistically significant difference between the grades $\left(\mathrm{x}^{2}=13.272 ; \mathrm{p}<0.001\right)$. Similarly, a statistically significant difference was observed between the fourth grade $(46.0 \%)$ and the first grade students (30.0\%), as far as the characteristic of a child with autism using echolalia-reverse usage of pronouns was concerned $\left(\mathrm{x}^{2}=5.458 ; \mathrm{p}<0.05\right)$. Overall, $37.6 \%$ of all respondents were aware of the echolalia speech in the current study.

Around $60.7 \%$ of all participants were of the opinion that a child with autism cannot participate in conversations. Approximately, $70.4 \%$ of the fourth grade students and $53.0 \%$ of the first grade students gave correct answer to this question, causing a 
Table I. Distribution of Correct Response Rates Given to Autism Awareness Assessment Questions according to grades

\begin{tabular}{|c|c|c|c|c|c|c|c|}
\hline & \multicolumn{6}{|c|}{ Correct response rate } & \multirow{3}{*}{$\begin{array}{l}\text { Chi-square } \\
\text { Significance }\end{array}$} \\
\hline & \multicolumn{2}{|c|}{$\begin{array}{c}\text { First grade } \\
\text { students }(n=100)\end{array}$} & \multicolumn{2}{|c|}{$\begin{array}{l}\text { Fourth grade } \\
\text { students(n=81) }\end{array}$} & \multicolumn{2}{|c|}{ Total(n=181) } & \\
\hline & $\mathrm{n}$ & $\%$ & $\mathrm{n}$ & $\%$ & $\mathrm{n}$ & $\%$ & \\
\hline Language delay & 91 & 91.0 & 67 & 82.7 & 158 & 87.3 & $\mathrm{x}^{2}=2.773 \mathrm{p}=0.096$ \\
\hline Impairment establishing eye-contact & 80 & 80.0 & 76 & 93.8 & 156 & 86.2 & $\mathrm{x}^{2}=7.187 \mathrm{p}=0.007^{\star}$ \\
\hline $\begin{array}{l}\text { Staring at spinning objects, TV, particularly } \\
\text { advertisements }\end{array}$ & 74 & 74.0 & 77 & 95.1 & 151 & 83.4 & $\mathrm{x}^{2}=14.351 \mathrm{p}=0.0006^{*}$ \\
\hline Autism is curable & 82 & 82.0 & 73 & 90.1 & 155 & 85.6 & $\mathrm{x}^{2}=2.401 \mathrm{p}=0.121$ \\
\hline Likes puzzles, sports, music, arts, math etc. & 54 & 54.0 & 45 & 55.5 & 99 & 54.7 & $\mathrm{x}^{2}=0.044 \mathrm{p}=0.834$ \\
\hline They might be aggressive from time to time & 53 & 53.0 & 57 & 70.4 & 110 & 60.8 & $x^{2}=5.664 p=0.017^{\star}$ \\
\hline Seen more frequently in males & 25 & 25.0 & 43 & 53.1 & 68 & 37.6 & $\mathrm{x}^{2}=15.051 \mathrm{p}=0.0001^{\star}$ \\
\hline Have hard time in social relations & 88 & 88.0 & 75 & 92.6 & 163 & 90.1 & $\mathrm{x}^{2}=1.053 \mathrm{p}=0.304$ \\
\hline Might have abnormal eating habits & 49 & 49.0 & 51 & 62.9 & 100 & 55.2 & $\mathrm{x}^{2}=3.528 \mathrm{p}=0.060$ \\
\hline Cannot express themselves using gestures & 42 & 42.0 & 56 & 69.1 & 98 & 54.1 & $\mathrm{x}^{2}=13.272 \mathrm{p}=0.0003^{*}$ \\
\hline Cannot participate in conversations & 53 & 53.0 & 57 & 70.4 & 110 & 60.7 & $x^{2}=5.664 p=0.017^{\star}$ \\
\hline Cannot play imaginative plays & 12 & 12.0 & 20 & 24.7 & 32 & 17.7 & $x^{2}=4.952 p=0.026^{*}$ \\
\hline Can imply a meaning by creating verbal expressions & 6 & 6.0 & 9 & 11.1 & 15 & 8.29 & $\mathrm{x}^{2}=1.538 \mathrm{p}=0.215$ \\
\hline $\begin{array}{l}\text { Spins around himself/ jumps repetitively/walks on } \\
\text { toes }\end{array}$ & 52 & 52.2 & 45 & 55.5 & 97 & 53.6 & $\mathrm{x}^{2}=0.227 \mathrm{p}=0.633$ \\
\hline Can harm himself by biting/hitting his head & 42 & 42.0 & 52 & 64.2 & 94 & 51.9 & $\mathrm{x}^{2}=8.833 \mathrm{p}=0.003^{\star}$ \\
\hline Is involved with parts of objects/toys & 70 & 70.0 & 66 & 81.5 & 136 & 75.1 & $\mathrm{x}^{2}=0.315 \mathrm{p}=0.075$ \\
\hline Attracts others' attention by their voices/ behaviors & 48 & 48.0 & 32 & 39.5 & 80 & 44.2 & $\mathrm{x}^{2}=1.309 \mathrm{p}=0.596$ \\
\hline Echolalia/reverse usage of pronouns & 30 & 30.0 & 38 & 46.0 & 68 & 37.6 & $\mathrm{x}^{2}=5.458 \mathrm{p}=0.019^{\star}$ \\
\hline Can use someone else's hand to reach things & 36 & 36.0 & 35 & 43.2 & 71 & 39.2 & $\mathrm{x}^{2}=0.976 \mathrm{p}=0.323$ \\
\hline
\end{tabular}

* Statistically significant $\mathrm{p}<0.05$

statistically significant difference between the grades $\left(x^{2}=5.664\right.$; $\mathrm{p}<0.05)$.

Nearly, $86.2 \%$ of all participants were aware that a child with autism can have impairment in establishing eye-contact; $93.8 \%$ of the fourth grade students and $80.0 \%$ of the first grade students gave correct answers to this question, creating a statistically significant difference between the grades $\left(\mathrm{x}^{2}=7.187 ; \mathrm{p}<0.05\right)$.

Similarly, a statistically significant difference was calculated between the fourth grade $(95.2 \%)$ and the first grade students (74.0\%) as far as 'staring at spinning objects, television, particularly advertisements, was considered as a characteristic of a child with autism $\left(\mathrm{x}^{2}=14.351 ; \mathrm{p}<0.05\right)$. This item was correctly answered by the majority of the whole group (83.4\%). One of the characteristics not distributed statistically significantly between the grades ( $\mathrm{p}>0.05$ ), but known by the majority of all participants (75.1\%) was "He is involved with parts of objects/toys".

In addition, there was a statistically significant difference in knowing that a child with autism cannot play imaginative games. This was marked by $17.7 \%$ of all students; $24.7 \%$ of fourth grades, $12.0 \%$ of first grades $\left(\mathrm{x}^{2}=4.952, \mathrm{p}<0.05\right)$.

As far as the strengths of a child having autism was questioned "Likes puzzles, sports, music, arts, mathematics, etc"was marked by $54.7 \%$ of all participants.

Ninety-two of the students (50.8\%) thought that a child having autism could disturb the teaching environment in the class (Table II). Of the fourth grade students, $70.4 \%$ thought that children having autism might be aggressive from time to time, this percentage was $53.0 \%$ among the first grade students, the difference being statistically significant $\left(\mathrm{x}^{2}=5.664 ; \mathrm{p}<0.05\right)$. Of all students, $51.9 \%$ thought that a child having autism can harm himself by biting or hitting his head, this percentage was $64.2 \%$ among the fourth grade and $42.0 \%$ among the first grade students; the difference being statistically significant $\left(\mathrm{x}^{2}=8.833\right.$; $\mathrm{p}<0.01)$. 
Table II. Distribution of responses of students to general questions about autism

\begin{tabular}{lc|}
$\begin{array}{l}\text { General questions about autism }{ }^{\dagger} \\
\text { 1.Marking World Autism Day true as April 2nd }\end{array}$ & $\begin{array}{c}\text { Percentage of } \\
\text { 'YES' responses } \\
\text { (\%) }\end{array}$ \\
$\begin{array}{l}\text { 2.Having attended a conference/project on autism before } \\
\text { 3.Having an acquaintance with autism }\end{array}$ & 12.7 \\
$\begin{array}{l}\text { 4.Having shared an indoor setting with an individual } \\
\text { having autism. }\end{array}$ & 10.5 \\
$\begin{array}{l}\text { 5.Thinking that a child having autism could pursue a } \\
\text { family life in the future with his/her spouse }\end{array}$ & 33.1 \\
$\begin{array}{l}\text { 6.Thinking that a child having autism could have healthy } \\
\text { children in the future }\end{array}$ & 46.3 \\
$\begin{array}{l}\text { 7.Thinking that a child having autism could disturb the } \\
\text { teaching environment in the class. }\end{array}$ & 50.8
\end{tabular}

${ }^{\dagger}$ There was no statistically significant difference in the percentage of YES responses among the first grade and fourth grade students $(\mathrm{p}>0.05)$

The majority (85.6\%) of the study group believed that autism is curable, the difference not demonstrating significance statistically between the grades ( $\mathrm{p}>0.05$ ).

Furthermore, there was a statistically significant difference in knowing that the autism is seen more frequently in males (53.1 $\%$ in fourth grades, $25.0 \%$ in first grades; $\left.\mathrm{x}^{2}=15.051, \mathrm{p}<0.001\right)$.

Around half of the participants (55.2\%) were aware that a child with autism might have abnormal eating habits, the difference not showing significance statistically between the grades ( $\mathrm{p}>0.05$ ).

The majority 140 (78.6\%) of the participants were found to mark World Autism Day true as April 2 $2^{\text {nd }}$; furthermore $23(12.7 \%)$ of the participants stated that they had attended a conference/ project on autism before. Nineteen (10.5\%) students admitted that they had an acquaintance having autism. Sixty (33.1\%) students declared that they had shared an indoor setting with an individual having autism (Table II). Around $94.5 \%$ of all students felt a lack of confidence in being able to meet the needs of pre-school children having autism in their class.

The mean autism awareness scores were compared between the first grade students $(9.1 \pm 3.7)$ and the fourth grade students $(11.2$ \pm 3.9 ). The difference was found to be statistically significant $(\mathrm{t}=3.75 ; \mathrm{p}<0.05)$.

\section{DISCUSSION}

In the current study, among all students of the Department of Pre-school Teacher Education of the public university, the bestknown characteristic of a child with autism was "having a hard time in social relations". The leading features of childhood autism were found to be "social interaction difficulties and lack of social responsiveness" in several studies [4, 6, 7, 9, 14-18]. "Making friends" is reported as a challenging issue for the children having autism $[3,14]$. In a review article by Gray and Tonge, the early features of autism were reported as "lack of interest in other children", lack of seeking to share own environment", "failure to develop peer relations", " failure to join in activities of others", and "lack of social play" [15]. In the London study, it is reported that children with autism actually seek friendships with others, but they do not have the skills to maintain them [19]. In DurandZaleski's study the elementary school teachers characterising autism as a social communication problem, resembled the findings of our study [20]. In Wang et al's study conducted on caregivers of pre-school children having autism in China, poor ability to communicate was the best-known characteristic of childhood autism [10]. A child with autism having difficulty in communicating and in social interactions was mentioned as the top - ranking characteristic of autism by primary school teachers in Pakistan in Arif et al's study [5]. Similar results appeared in Lian et al's study conducted on pre-school teachers in Singapore [7] and in Liu et al's study also carried out on preschool teachers in China [8].

In our study, the majority of the respondents were aware that a child having autism can have language delay. More than half of them were of the opinion that a child with autism cannot participate in conversations. Approximately one third of all respondents were aware of the echolalia speech-reverse usage of pronouns in the current study. Delay in speaking was reported to be one of the signs of childhood autism. [7,9,17, 18, 21-24]. Actually, Heidgerken et al. imply that even if children falling within the lower end of the spectrum can often achieve adequate functioning in language and social behavior, they can still retain some persistent speech and behavioural pecularities [23]. Some children with autism can sometimes never speak; they can use words in different meanings, they can misuse the pronouns, they can have echolalia, they cannot start or continue a conversation $[15,22,24]$. In Arif et al's study, individuals with autism are stated to exhibit varying verbal abilities, ranging from being nonverbal to having advanced speech [5]. The questions inquiring language delay, initiating or responding to conversation and other speech problems like echolalia were better known by the participants of our study as compared to the participants of Karabekiroğlu et al's, Wang et al's, Arif et al's and Liu et al's studies $[5,8,10,25]$. Being aware of language delay appeared with similar percentages in our study as in Lian et al's study [7].

In our study, the majority of all participants were aware that a child with autism can have impairment in establishing eyecontact. Around half of the participants were aware that children having autism cannot express themselves using gestures. These children are most of the time reported to have difficulty with not only verbal but also with nonverbal communication such as lack of eye-contact, lack of gesture, lack of facial expression, lack of social responsiveness, disliking social touch with almost no social smile $[4,7,15,17,18,24]$. Resembling the findings of our study, in another Turkish study carried out in elementary school teachers, around half of the respondents stated that children with autism have difficulty maintaining eye-contact [25]. Yasar and Cronin's study conducted on College of Education Students in Ankara and Trabzon in Turkey, similar findings emerged [26]. Poor eye-contact, gesture, and social responsiveness were stated in similar ratios to our study in Arif et al's, Liu et el al's, Wang 
et al's and Lian et al's studies $[5,7,8,10]$. The characteristics of childhood autism namely "staring at spinning objects, televison, particularly advertisements" and "being involved with parts of objects/toys" were marked by the majority of the respondents in our study. Gazing at objects, staring into space for long periods of time, being occupied with parts of objects can be seen as characteristics of small children with autism [15,18,21,27,28]. As far as the characteristic of "staring at spinning objects, television, particularly advertisements" was concerned, the awareness percentage of our participants showed similarity with Karabekiroğlu et al's study from Turkey [25]. A characteristic of childhood autism less known by our participants was "cannot play imaginative games". Some of the small children having autism are reported as not using toys appropriately, such as lining them up rather than imaginative or pretend games and also that they prefer not to imitate other children during play $[7,9,15,17,18,21,24,27,28]$.

As far as the strengths of a child having autism was questioned "Likes puzzles, sports, music, arts, math etc"was marked by around half of all participants in our study. This percentage was higher in the current study as compared to Wang et al's study [10]. It is recommended by Yasar and Cronin that not only families but also educators must be aware of these strengths for the social and intellectual development of these children and for them to be better accepted by the community in Turkey [26].

Among the emerging pessimistic thoughts in our study was that nearly half of the respondents' believed that a child having autism could disturb the teaching environment in the class. Furthermore, approximately half of the respondents thought that children having autism might be aggressive from time to time and also that a child having autism can harm himself by biting or hitting his head. In severe forms of autism, aggressive behaviors like severe temper tantrums and/or frequent minor tantrums; hurting others by biting, hitting, kicking; hurting self by biting the hand or banging the head may be seen [28]. Impatience when waiting for needs to be met; often being frightened or very anxious: being oblivious to dangerous situations, might also present in severe forms according to Krug et al. [28]. However, these problematic situations exist in a minority of these children; besides, they exist in trivial degrees in children having mild to moderate forms of autism [6$9,17,26]$. Most of the time, after behavioral and social training conducted at early ages, they might often be easy to manipulate $[6-9,17,26]$. In McConkey and Bhlirgri's study, the most difficult problems the pre-school teachers found hard to deal with were temper tantrums [9]. In countries where children broadly attend pre-school from an early age like in Sweden, Early Intensive Behavioral Intervention (EIBI) programmes in young children with autism are largely delivered by regular pre-school staff [6, 29]. These EIBI methods are also being recommended by Liuet et al., Lian et al., McConkey and Bhlirgri, Stichter et al. and Yasar and Cronin [7-9,17,26]

It is stated that children with autism are also at risk of being harmed, ignored or nagged in the classroom, for example they are more likely to be bullied [30,31]. In Humprey and Symes's study, the respondents felt that the key benefits mainstream pupils without autism would gain from a child with autism integrated into mainstream was increased understanding and tolerance of people different to themselves [30]. In McConkey and Bhlirgri's study, it is reported that not only the children having autism would benefit from inclusion but also their normally developing peers [9].

The majority of the study group believed that autism is curable. One of the recent review articles written by Ratajczak and Sothern discuss autism's being no longer considered as incurable [32]. In this article, non-categorical pre-school classes, individual speech therapy, applied behavioral analysis, together with other behavioral and social interventions are discussed, as well as the effects of sulforaphane, malariotherapy, fever and various other therapies in the treatment of autism [32]. A considerable ratio of the early detected children with autism were reported to have optimal outcome, that is losing all symptoms in addition to the diagnosis [32]. Similarly, a study carried out by Mukaddes et al., in Turkey, after Early Intensive Behavioral Intervention (EIBI), Pivotal Response Training (PRT) and comprehensive naturalistic behavioral programme, a group of children having autism recovered [33]. In Mukaddes et al's study, collaboration between Families, Nursery Teachers, Speech Therapists and Special Educators were among the determinants for achieving recovery [33].

As far as the overall findings of our study are concerned, the general awareness of pre-school teaching students concerning childhood autism was better than the participants of the Wang et al's, Arif et al's and Liu et al's studies [5, 10]. However, around the majority of the participants declared that they did not feel confident in being able to meet the needs of pre-school children having autism in their class. Similar feelings were reported in Liuet et al's, Humprey and Symes' and McConkey and Bhlirgri's studies $[8,9,30]$; whereas in Sweden, pre-school teachers felt more secure about their approach to the children having autism in Andersson et al's study [29]. In Yasar and Cronin's study conducted on College of Education students in Turkey, students admitted that they had basic knowledge about autism, but they needed more inclusive and in-depth knowledge [26].

Few of the students in our study admitted that they had an acquaintance having autism. Around one third declared that they had shared an indoor setting with an individual having autism. In Yasar and Cronin's study, most of the students stated that they did not know any individual with autism and they had never experienced teaching a child with autism during their practicum hours [26].

Inclusive education began in Turkey in 1983 with the regulation regarding children with special needs. In Turkey, even though there are legal requirements about special education services and inclusive education, there is a scarcity of trained educators to provide those services and there are no well-designed educational environments for inclusive education [26].

In 2006, all teacher training programs in Turkey were required to add special education and inclusion classes to their programs [26]. However, few of the Universities in Turkey have a program which can educate teachers and specialists for students with 
autism, because there are not enough university professionals who can prepare the teachers who will serve students with autism in special education and inclusive settings as Yasar and Cronin stated in their article [26]. To this end, Turkey needs professionals who can work on autism, and also academic staff who can develop college training programs [26].

Diagnosis of autism at younger ages plays a crucial role in prognosis and developmental outcomes. Outside of parents and care-givers, pre-school teachers are the group most likely to spend the longest time and the closest relations with small children having autism in the early years of life. The role of preschool teachers is not only timely recognition and referral of these children; but also their intellectual, social and behavioural management; together with parent support in cooperation with health authorities.

In the current study, around half of the respondents thought that a child having autism could disturb the teaching environment in the class. Those problematic situations actually exist in a minority of these children; besides, they exist in trivial degrees in children having mild-moderate forms of autism. Most of the time after behavioral and social training conducted at early ages, they might often be easy to manipulate. However, around the majority of the participants of our study declared that they did not feel confident in being able to meet the needs of preschool children having autism in their class. To this end, after this study, we believe that our study group needs further training on timely picking up these children in the classroom, on their intellectual, social and behavioural management; manipulation of problematic behaviour and also being a role model for the normally developing children for their attitutes towards their peers with autism. The most important of all is that they must not discriminate the children with autism and prevent discrimination within the classroom. In Turkey, although all teacher training programs are required to add special education and inclusion classes to their programs, most of the time they do not have well-designed educational environments for inclusive education. Furthermore, few of the Universities in Turkey have a program which can prepare teachers and specialists for students with autism, because there are not enough university professionals who can prepare the teachers who will serve students with autism in special education and inclusive settings.

\section{Limitations}

Several questions relating to childhood autism were not covered in our study. Besides, the results of this study cannot be generalized to Istanbul Province or to Turkey as a whole. Nevertheless, it can serve as a guide to further studies. This study using a self-administered questionnaire can also present the limitation of reporting bias and desirability for providing right answers.

\section{Conclusion}

The autism awareness of the respondents of our study could be considered to be relatively good. The respondents can be interpreted as belonging to a group of people between the general public and educators. Therefore, this study is important for the early detection of autism and early intervention, and also for decreasing any discrimination present in the community. Autism spectrum disorders could be integrated into the curricular or extracurricular theoretical and practical courses of all colleges of education; particularly pre-school teaching, awareness of educators can be raised to very high levels. This is almost essential, keeping in mind the fast increase in autism prevalence.

Adequate knowledge and awareness about childhood autism among educators would ensure early detection of children with autism in the community and this in turn would allow early intellectual, social and behavioural interventions.

\section{Compliance with Ethical Standards}

Ethical Approval: This study was approved by Marmara University Ethics Committee. All procedures performed in this study were in accordance with the ethical standards of the institutional and national research committee and with the 1964 Helsinki declaration and its later amendments or comparable ethical standards.

Funding: The authors received no financial support for the study.

Conflict of Interest: The authors declare that they have no conflict of interest. Informed Consent: Informed consent was obtained from all participants. Authors' Contributions: Concept and Design - SH, NEM; Supervision - MK; Resources - SH, NEM; Materials - SH, MK; Data Collection and Processing - SH, NEM, MK; Analysis and Interpretation - SH, ŞGK; Literature Search - SH, NEM; Writing Manuscript - MK; Critical Review - AK, MK

\section{REFERENCES}

[1] J Udhya, MM Varadharaja, J Parthiban. Autism disorder (AD): An updated review for paediatric dentists. J Clin Diagn Res 2014;8:275-9. doi: 10.7860/JCDR/2014/7938.4080

[2] Elsabbagh M, Divan G, Koh YJ, et al. Global prevalence of autism and other pervasive developmental disorders. Autism Res 2012;5:160-79. doi: 10.1002/aur.239

[3] Dillenburger K, Jordan JA, McKerr L. Autism spectrum disorder: public awareness and attitudes. Research Update 2013;84:1

[4] Hartley-McAndrew M, Doody KR, Mertz J. Knowledge of autism spectrum disorders in potential first-contact professionals. N Am J Med Sci 2014;7:97-102.

[5] Arif MM, Niazy A, Hassan B, Ahmed F. Awareness of autism in primary school teachers. Autism Res Treat 2013;2013. doi: $10.1155 / 2013 / 961595$

[6] Langh U, Hammar M, Klintwall L, Bolte S. Allegiance and knowledge levels of professionals working with early intensive behavioural intervention in autism. Early Interv Psychiatry 2016;5:444-50. doi: 10.1111/eip.12335

[7] Lian WB, Ying SH, Tean SC, et al. Pre-school teachers' knowledge, attitudes and practices on childhood developmental and behavioural disorders in Singapore. J 
Paediatr Child Health 2008;44:187-94. doi: 10.1111/j.14401754.2007.01231.x

[8] Liu Y, Li J, Zheng Q, et al. Knowledge, attitudes, and perceptions of autism spectrum disorder in a stratified sampling of preschool teachers in China. BMC Psychiatry 2016;16:142. doi: 10.1186/s12888.016.0845-2

[9] McConkey R, Bhlirgri S. Children with autism attending preschool facilities: The experiences and perceptions of staff. Early Child Dev Care 2003;173:445-52.

[10] Wang J, Zhou X, Xia W, et al. Autism awareness and attitudes towards treatment in caregivers of children aged 3-6 years in Harbin, China. Soc Psychol Psychiatr Epidemiol 2012;47:13018. doi: $10.1007 / \mathrm{s} 00127.011 .0438-9$

[11] Öner P, Öner Ö, Çöp E, Munir KM. Reliability and validity of the Turkish version of the social communication scale. Bulletin of Clinical Psychopharmacology 2012;22:43-50. doi:

[12] Kara B, Mukaddes NM, Altinkaya I, et al. Using the modified checklist for autism in toddlers in a well-child clinic in Turkey: adapting the screening method based on culture and setting. Autism 2014;18:331-8. doi: 10.5455/bcp.201.112.12091514

[13] Bakare MO, Ebigbo PO, Agomoh AO, Menkiti NC. Knowledge about childhood autism among health workers (KCAHW) questionnaire: description, reliability and internal consistency. Clin Pract Epidemiol Ment Health 2008;4:17. doi: $10.1177 / 136.236 .1312467864$

[14] Dillenburger K, Jordan JA, McKerr L, Devine P, Keenan M. Awareness and knowledge of autism and autism interventions: A general population survey. Research in Autism Spectrum Disorders 2013;7:1558-67.

[15] Gray KM, Tonge BJ. Are there early features of autism in infants and preschool children? J Paediatr Child Health 2001;37:221-6. doi: 10.1046/j.1440-1754.2001.00653.x

[16] Imran N, Chaudry MR, Azeem MW, et al. A survey of Autism knowledge and attitudes among the healthcare professionals in Lahore, Pakistan. BMC Pediatr 2011;11:107. doi:10.1186/1471-2431-11-107

[17] Stichter JP, Riley-Tillman TC, Jimerson SR. Assessing, understanding, and supporting students with autism at school: Contemporary science, practice, and policy. Sch Psychol Q 2016;31:443-9. doi: 10.1037/spq0000184

[18] Zwaigenbaum L, Bryson S, Garon N. Early identification of autism spectrum disorders. Behav Brain Res 2013;251:133-46. doi: 10.1016/j.bbr.2013.04.004

[19] Engelhardt J. The understanding and perceptions of teaching assistants working with children with autism. Good Autism Practice (GAP) 2014;15:22-33.

[20] Durand-Zaleski I, Scott J, Rouillon F, Leboyer M. A first national survey of knowledge, attitudes and behaviours towards schizophrenia, bipolar disorders and autism in France. BMC Psychiatry 2012;12:128. doi: 10.1186/1471-244X-12-128
[21] Committee on Children with Disabilities. The pediatrician's role in the diagnosis and management of autistic spectrum disorder in children. Pediatrics 2001;107:1221-6. doi: 10.1542/ peds.107.5.e85

[22] Bodur Ş, Soysal AŞ. Otizmin erken tanısı ve önemi. STED, 13 (10) 2004:394-8.

[23] Heidgerken AD, Geffken G, Modi A, Frakey L. A survey of autism knowledge in a health care setting. J Autism Dev Disord 2005;35:323-30. doi: 10.1007/s10803.005.3298-x

[24] Nygren G, Sandberg E, Gillstedt F, et al. A new screening programme for autism in a general population of Swedish toddlers. Res Dev Disabil 2012;33:1200-10. doi: 10.1016/j. ridd.2012.02.018

[25] Karabekiroğlu K, Cakin-Memik N, Ozcan-Ozel O, et al. Stigmatization and Misinterpretations on ADHD and Autism: A Multi-Central Study with Elementary School Teachers and Parents. Turkish Journal of Clinical Psychiatry 2009;12:79-89.

[26] Yasar P, Cronin KA. Perspectives of college of education students in Turkey on autism spectrum disorders. Int J Spec Educ 2014;29:61-75.

[27] Igwe MN, Bakare MO, Agomoh AO, Onyeama GM, Okonkwo KO. Factors influencing knowledge about childhood autism among final year undergraduate Medical, Nursing and Psychology students of University of Nigeria, Enugu State, Nigeria. Ital J Pediatr 2010;36:44. doi: 10.1186/1824-7288-36-44

[28] Krug DA, Arick J, Almond P. Behavior checklist for identifying severely handicapped individuals with high levels of autistic behavior. J Child Psychol Psychiatry 1980;21:221-9. doi: 10.1111/j.1469-7610.1980.tb01797.x

[29] Andersson GW, Miniscalco C, Gillberg C. Preschoolers assessed for autism: parent and teacher experiences of the diagnostic process. Res Dev Disabil 2014;35:3392-402. doi: 10.1016/j.ridd.2014.08.027

[30] Humphrey N, Symes W. Inclusive education for pupils with autistic spectrum disorders in secondary mainstream schools: teacher attitudes, experience and knowledge. Int J Inc Educ 2013;17:32-46.

[31] Mavropoulou S, Sideridis GD. Knowledge of autism and attitudes of children towards their partially integrated peers with autism spectrum disorders. J Autism Dev Disord 2014;44:1867-85. doi: 10.1007/s10803.014.2059-0

[32] Ratajczak HV, Sothern RB. Positive Effect of Fever on Symptoms of Autism. N Am J Med Sci 2016;9:167-71

[33] Mukaddes NM, Tutkunkardas MD, Sari O, Aydin A, Kozanoglu P. Characteristics of children who lost the diagnosis of autism: a sample from istanbul, Turkey. Autism Res Treat 2014;2014. doi: $10.1155 / 2014 / 472120$ 